RAND RESEARCH AREAS

CHILDREN AND FAMILIES EDUCATION AND THE ARTS ENERGY AND ENVIRONMENT HEALTH AND HEALTH CARE INFRASTRUCTURE AND TRANSPORTATION

INTERNATIONAL AFFAIRS

LAW AND BUSINESS

NATIONAL SECURITY

POPULATION AND AGING

PUBLIC SAFETY

SCIENCE AND TECHNOLOGY

TERRORISM AND

HOMELAND SECURITY
This fact sheet is part of the RAND Corporation research brief series. RAND fact sheets summarize published, peerreviewed documents.

Headquarters Campus 1776 Main Street P.O. Box 2138 Santa Monica, California 90407-2138

TEL 310.393 .0411

FAX 310.393 .4818

(c) RAND 2010

\title{
Studies' Estimates of PTSD Prevalence Rates for Returning Service Members Vary Widely
}

$\mathrm{n}$ allocating resources to treat posttraumatic stress disorder (PTSD) among service members, policymakers rely on estimates of how prevalent this condition is among troops. But published prevalence rates vary extensively and are often disputed. For example, the most frequently cited estimate for PTSD among Vietnam veterans_-nearly 31 percent—is still highly criticized. Similar concerns have been raised about PTSD prevalence estimates among U.S. service members serving in Afghanistan as part of Operation Enduring Freedom (OEF) and in Iraq as part of Operation Iraqi Freedom (OIF).

A team of RAND researchers analyzed the literature to document the extent of the variation in PTSD prevalence rates for military personnel who had served in OEF and OIF since 2002 and to identify possible explanations for these discrepancies. The team found 29 relevant studies and documented the following findings:

- PTSD prevalence rates vary widely. The studies reported 62 different prevalence estimates, ranging overall from around 1 percent to 60 percent. Those estimates greater than 20 percent were mostly seen among samples of veterans seeking treatment, many of whom were exposed to combat and were injured while deployed. In more general samples representative of previously deployed personnel, rates were commonly 5 percent to 20 percent, based primarily on self-reported symptoms on questionnaires. However, for both personnel seeking treatment and those in the more general samples, the estimates varied widely because of the different study populations and the different diagnostic definitions used to determine PTSD, as described next.

- Some of this variation is related to the different methods used to define PTSD... The studies used 14 different methods to define PTSD. When different definitions were applied to the same studies, the resulting estimates varied significantly.

- ... and to the different study samples. The studies reported prevalence rates across a variety of study samples, from a single Army unit to groups of service members wounded in battle. Few samples were representative of all those who had deployed. Estimating PTSD from different samples can overestimate or underestimate the rate.

- Not all studies published the statistical precision of their prevalence estimates. All but two studies reported estimates as a single number rather than a more-precise range (confidence interval) to account for sampling error. Some of the highest estimates of PTSD prevalence in the studies were the least statistically precise.

- Only combat exposure was consistently associated with PTSD. This correlation held after examination of seven other factors most associated with PTSD: injury, component (active or reserve/National Guard), gender, race, deployment location (Iraq or Afghanistan), age, and rank.

Continued on back

This fact sheet is based on Ramchand R, Schell TL, Karney BR, Osilla KC, Burns RM, Caldarone LB, "Disparate prevalence estimates of PTSD among service members who served in Iraq and Afghanistan: Possible explanations," Journal of Traumatic Stress, February 2010. As of February 10, 2010: http://www3.interscience.wiley.com/cgi-bin/fulltext/123274990/PDFSTART 
As a result of their analyses, the study team urged both researchers and policymakers to consider the methods used to derive prevalence estimates, and the confidence intervals around those estimates, when evaluating the usefulness of these data. To improve the reliability of future estimates, they recommended that (a) the method used to define PTSD should be consistent across studies, (b) the method should be well validated for estimating PTSD prevalence among military personnel, and (c) estimates should control for differential exposure to combat across samples.

Office of Congressional Relations | $703-413-1100 \times 5320$ | ocr@rand.org | www.rand.org/congress

This fact sheet was written by Elizabeth Maggio. The RAND Corporation is a nonprofit research organization providing objective analysis and effective solutions that address the challenges facing the public and private sectors around the world. RAND's publications do not necessarily reflect the opinions of its research clients and sponsors. RAND ${ }^{\circledR}$ is a registered trademark.

RAND Offices

Santa Monica, CA • Washington, DC • Pittsburgh, PA • New Orleans, LA/Jackson, MS • Boston, MA • Doha, QA • Cambridge, UK・ Brussels, BE 
THE ARTS

CHILD POLICY

CIVIL JUSTICE

EDUCATION

ENERGY AND ENVIRONMENT

HEALTH AND HEALTH CARE

INTERNATIONAL AFFAIRS

NATIONAL SECURITY

POPULATION AND AGING

PUBLIC SAFETY

SCIENCE AND TECHNOLOGY

SUBSTANCE ABUSE

TERRORISM AND HOMELAND SECURITY

TRANSPORTATION AND INFRASTRUCTURE

WORKFORCE AND WORKPLACE
This PDF document was made available from www.rand.org as a public service of the RAND Corporation.

This product is part of the RAND Corporation research brief series. RAND research briefs present policy-oriented summaries of individual published, peerreviewed documents or of a body of published work.

The RAND Corporation is a nonprofit research organization providing objective analysis and effective solutions that address the challenges facing the public and private sectors around the world.

\section{Support RAND}

$\underline{\text { Browse Books \& Publications }}$

Make a charitable contribution

\section{For More Information}

Visit RAND at www.rand.org

Explore the RAND Center for Military Health Policy Research

View $\underline{\text { document details }}$

Limited Electronic Distribution Rights

This document and trademark(s) contained herein are protected by law as indicated in a notice appearing later in this work. This electronic representation of RAND intellectual property is provided for non-commercial use only. Unauthorized posting of RAND PDFs to a non-RAND Web site is prohibited. RAND PDFs are protected under copyright law. Permission is required from RAND to reproduce, or reuse in another form, any of our research documents for commercial use. For information on reprint and linking permissions, please see RAND Permissions. 